\title{
Determinants of Mixed Infant Feeding Practice Among HIV Positive Mothers Attending PMTCT and ART Services in Southern Ethiopia: A Case-control Study
}

\author{
Beminet Moges Gebremariam ${ }^{1, ~ *, ~ E r m i a s ~ A b e r a ~ T i r u s e ~}{ }^{1}$, Biruk Assefa Kebede ${ }^{2}$, \\ Million Mohammed Asfaw ${ }^{3}$ \\ ${ }^{1}$ Department of Public Health, College of Medicine and Health Sciences, Wachemo University, Hosanna, Ethiopia \\ ${ }^{2}$ Department of Midwifery, College of Medicine and Health Sciences, Wachemo University, Hossana, Ethiopia \\ ${ }^{3}$ Department of Surgery, School of Medicine, College of Medicine and Health Sciences, Wachemo University, Hosanna, Ethiopia
}

Email address:

bemnismart@gmail.com (B. M. Gebremariam)

${ }^{*}$ Corresponding author

\section{To cite this article:}

Beminet Moges Gebremariam, Ermias Abera Tiruse, Biruk Assefa Kebede, Million Mohammed Asfaw. Determinants of Mixed Infant Feeding Practice Among HIV Positive Mothers Attending PMTCT and ART Services in Southern Ethiopia: A Case-control Study. Science Journal of Public Health. Vol. 9, No. 5, 2021, pp. 154-161. doi: 10.11648/j.sjph.20210905.13

Received: May 23, 2021; Accepted: July 8, 2021; Published: September 14, 2021

\begin{abstract}
Background and aim: Infant feeding practices recommended to mothers known to be living with HIV should support the greatest likelihood of the HIV-free survival of their children and not harm the health of mothers. HIV positive women are confused about feeding methods and mixed feeding continued to be widespread. The determinant of infant mixed feeding practice among HIV positive mothers is not well studied in Ethiopia. The aim of the study is to assess the determinants of mixed infant feeding practice among HIV Positive Mothers in Southern Ethiopia. Methods: Unmatched case-control study was conducted among HIV positive mothers at selected ART centers of Southern Ethiopia. A total of 276 mothers children pair; 92 cases and 184 controls, were enrolled in the study. An interviewer-administered questionnaire was used to collect data and EPI info version 3.5.3 statistical software used to enter data and analysis was done using SPSS version 20software. Bivariate and multivariate logistic regression was carried out to identify the determinants of mixed feeding practice of HIV positive mothers. Result: Determinants which are significantly associated with mixed infant feeding practice of HIV positive mothers were: Age group 15-35years ( $\mathrm{AOR}=3.90$; 95\% CI: 1.59-9.56); Home delivered mothers (AOR=8.79; 95\% CI: 3.08, 25.10); HIV diagnosed five and above years ago ( $\mathrm{AOR}=1.85 ; 95 \% \mathrm{CI}: 1.02-3.39$ ) and WHO Clinical stage I (AOR=2.47; 95\% CI: 1.23, 4.94). Conclusion: The study concludes that, age of the mother, place of delivery, duration since mother HIV diagnosed, and WHO clinical stage of the mother was identified as determining factors of mixed infant feeding practice. There is a positive relationship between HIV test results of infants and mixed feeding practice of HIV positive mothers. An integrated infant feeding counseling with a practical demonstration is needed to foster HIV positive mother's practice on infant feeding options. Moreover, enhancement of health facility delivery, HIV care service through the implementation of new WHO Infant feeding global guidelines was critically mandatory for the HIV free survival of children.
\end{abstract}

Keywords: HIV Exposed Infants, HIV Positive Mothers, PMTCT, ART, Mixed Infant Feeding Practice

\section{Introduction}

HIV infection among infants primarily transmitted from mothers. Mother-to-child transmission (MTCT) can take place when the child is still in the mother's womb, around the time of birth, or through breastfeeding after birth. The risk though breastfeeding is cumulative; the longer the HIVinfected mother breastfeeds, the greater the additional risk of transmission through breastfeeding. Where breastfeeding is common and prolonged, transmission through breastfeeding may account for up to half of HIV infections in infants and young children [1]. In 2015, an estimated 150,000 children (aged 0-14 years) were newly infected with HIV globally, 
and nearly 85 percent of them live in sub-Saharan Africa. About 65,000 (53\%) of new infections among sub-Saharan children occur due to post-natal HIV infections (after the first six weeks of life) [2].

The 2016 World Health Organization Updated guidelines indicated that infant feeding practices recommended to mothers known to be living with HIV should support the greatest likelihood of the HIV-free survival of their children and not harm the health of mothers. Mothers living with HIV and health-care workers can be reassured that ART reduces the risk of postnatal HIV transmission in the context of mixed feeding. Although exclusive breastfeeding is recommended, practicing mixed feeding is not a reason to stop breastfeeding in the presence of ARV drugs. Mothers known to be living with HIV should exclusively breastfeed their infants for the first six months of life, introducing appropriate complementary foods thereafter and continue breastfeeding for the first 12 months of life. Breastfeeding should then only stop once a nutritionally adequate and safe diet without breast milk can be offered. When mothers known to be living with HIV decide to stop breastfeeding at any time, infants should be provided with safe and adequate replacement feeds to enable normal growth and development [3]. Without intervention to prevent mother-to-child transmission, $30-45 \%$ of infants born to HIV-positive mothers in developing countries become infected during pregnancy, delivery, and breastfeeding but it does not solve the problem of infant feeding which is responsible for as much as $5-20 \%$ of infections [4].

Mixed-fed infants due to the increased risk of diarrhea to the infant associated with unhygienic and unsafe environments and the use of unsafe water for formula preparation. Other foods and liquids alter the infant's gastrointestinal integrity and may therefore facilitate MTCT of HIV [5]. Exclusive breastfeeding for the first six months of the infant's life carries a 4-10-fold decreased risk of MTCT of HIV compared to mixed breastfeeding [6]. Research evidenced that compared to those who practiced mixed feeding the risk of mother to child transmission is lower among mothers who exclusively breastfed when. In addition, exclusive replacement feeding (ERF) is associated with a low risk of postnatal HIV transmission and high mortality when compared to breastfeeding [7-10].

According to 2012 HIV Related Estimates and Projections for Ethiopia by EPHI, the adult HIV prevalence for 2014 is estimated at $1.2 \%$ of which $3.3 \%$ is urban and $0.5 \%$ is rural. The estimated numbers of children with HIV 138,906 need ARV treatment [11]. In Ethiopia over 200,000 children under-five are HIV positive. The risk of transmission varies with the duration of breastfeeding, but it is estimated to be about $10-20 \%$ for those breastfed for two years [12]. However, there is a paucity of literature in SNNPR and the study area particularly in the health facilities of hosanna town. Therefore, this study aimed to identify the determinants of mixed infant feeding practices among HIV positive mothers attending PMTCT and ART services in the selected facilities of Southern Ethiopia.

\section{Methods and Materials}

\subsection{Study Design, Area and Period}

Unmatched Case-control study design was conducted in 4 randomly selected ART and PMTCT service providing public Hospitals (includes: Wachemo University Nigest Elleni Mohammed Memorial Teaching hospital, Worabe Comprehensive specialized hospital, Halaba General hospital, and Wolita Sodo University Teaching Specialized hospital) found in 4 zones of South Nation Nationality Peoples Region of Ethiopia. The study was done from November 5 to December 30, 2018.

\subsection{Population}

All HIV positive mothers who have HIV exposed children less than 2 years attending PMTCT and ART clinics in selected public Hospitals of southern Ethiopia. Cases were HIV positive mothers attending PMTCT and ART who practiced mixed feeding for their infants. Controls were HIV positive mothers attending PMTCT and ART who practiced standard infant feeding. Those severely ill mothers were excluded from the study.

\subsection{Sample Size Determination and Procedure}

The sample size was calculated using Open Epi version 3.5.3 statistical software. The sample size was calculated by taking a mother who fed mixed feeding as an exposure variable. From literature, it was found that the proportion of HIV positive mothers practiced recommended infant feeding in Southwestern Nigeria $87 \%$ [13]. By considering 95\% of confidence interval, $80 \%$ power, Odds ratio of 6.8 mothers who have an ill infant more likely to practice Mixed Feeding, and case to control the ratio of $1: 2$ and an additional 5 percent added for non-response; then the total sample size was 276 children (92 cases and 184 controls). A systematic random sampling technique was employed to select the subject from 4 governmental health facilities until the required sample size are fulfilled from sample frames. Sampling frames were prepared for each health facility based on previous year one-month records. Starting from a random point from the sampling frames, every kth element in the frame was selected at equal intervals (sampling interval) from proportional allocated numbers for each health center. The size of numbers allocated for each health facilities based on the catchment area under 2 years population.

\subsection{Data Collection Procedures}

Data on determinants of mixed infant feeding practice among HIV positive mothers in Southern Ethiopia was collected using a structured questionnaire. An intervieweradministered closed-ended questionnaire was used to collect the data adapted from WHO, and after reviewing the literatures of similar studies. To ensure the quality of data, a pre-test of data collection tools was done among HIV positive mothers in the Fonko ART clinic by taking $5 \%$ of the respondents of the total sample size and necessary correction 
was done after the tools pre-tested. The collected data were checked out for completeness and clarity by the principal Investigators and supervisors. Data clean up and crosschecking was done before analysis.

\subsection{Data Processing and Analysis}

After coding the data was entered and analyzed by using SPSS version 20. Descriptive statistics was carried out to compute different frequencies, percentages, and different diagrams. To find the determinants of infant feeding practice binary logistic regression was applied and the variables $(p \leq 0.2)$ which associated with the outcome variable was entered into the multivariate analysis to control confounding factors. Finally, the variables which had a significant association was identified based on $p$-value $\leq 0.05$ and AOR, with $95 \% \mathrm{CI}$ to measure the strength of the associations.

\subsection{Definition of Terms}

1) Mixed Feeding: an infant younger than 6 months of age is given other liquids and/or foods together with breast milk. This could be water, other types of milk, or any type of solid food [3].

2) Exclusive breastfeeding: the infant receives only breast milk without any other liquids or solids, not even water, except for oral rehydration solution or drops or syrups of vitamins, minerals, or medicines [3].

3) Replacement feeding: feeding an infant who is not receiving any breast-milk with a diet that provides all the nutrients children need until they can be fully fed on family foods. During the first six months, this should be with a suitable breast milk substitute: commercial infant formula milk [3].

4) Standard Feeding: an infant younger than 6 months of age fed exclusive breastfeeding or Exclusive replacement feeding.

\subsection{Ethical Considerations}

Ethical clearance was obtained from the ethical review board of Wachemo University. An official permission letter was sent to ART centers in which the actual data collection was undertaken. The purposes and importance of the study were explained and written informed consent was secured from each participant. Confidentiality was maintained at all levels of the study. Participant's involvement in the study was on a voluntary basis; participants who were unwilling to participate in the study informed to quit their participation at any stage without any restriction.

\section{Results}

\subsection{Socio-demographic Characteristics of Infants and Parents}

A total of 276 mothers were interviewed. Ninety-two were cases and 184 were controls. From sampled mothers of children, $75(27.2 \%)$ cases and $119(43.1 \%)$ controls were found within the age group 25-35years. In the case of marital status, $84(30.4 \%)$ of mixed fed infants and $158(52.2 \%)$ of the standard fed infants were married. The main occupation among women was a housewife in $55(19.9 \%)$ cases and 92 $(33.3 \%)$ controls. Only 8 cases $(2.9 \%)$ and 29 (10.5\%) controls had attained above secondary education among mothers. Seventy-one (25.7\%) of cases and 157 (56.9\%) controls were residing in urban (Table 1).

Table 1. Socio demographic characteristics of children and parents of HIV positive mothers in Southern Ethiopia 2019 (n: 276).

\begin{tabular}{|c|c|c|}
\hline \multirow[t]{2}{*}{ Variables } & \multirow{2}{*}{$\begin{array}{l}\begin{array}{l}\text { Cases (Mixed } \\
\text { feeding) }\end{array} \\
\mathrm{n}(\%)=92 \\
\end{array}$} & \multirow{2}{*}{$\begin{array}{l}\text { Controls } \\
\text { (Standard feeding) } \\
\text { n }(\%)=184 \\
\end{array}$} \\
\hline & & \\
\hline \multicolumn{3}{|l|}{ Sex of Child } \\
\hline Male & $44(15.9 \%)$ & $111(40.2 \%)$ \\
\hline Female & $48(17.4 \%)$ & $73(26.4 \%)$ \\
\hline \multicolumn{3}{|l|}{ Age of mother in yrs } \\
\hline $15-24$ & $7(2.5 \%)$ & $53(19.2 \%)$ \\
\hline $25-35$ & $75(27.2 \%)$ & $119(43.1 \%)$ \\
\hline $35+$ & $10(3.6 \%)$ & $12(4.3 \%)$ \\
\hline \multicolumn{3}{|c|}{ Marital status of the mother } \\
\hline Married & $84(30.4 \%)$ & $158(57.2 \%)$ \\
\hline Divorced & $4(1.4 \%)$ & $16(5.8 \%)$ \\
\hline Widowed & $4(1.4 \%)$ & $2(0.7 \%)$ \\
\hline Single & $0(0.0 \%)$ & $8(2.9 \%)$ \\
\hline \multicolumn{3}{|l|}{ Religion } \\
\hline Protestant & $43(15.6 \%)$ & $75(27.2 \%)$ \\
\hline Orthodox & $45(16.3 \%)$ & $101(36.6 \%)$ \\
\hline Muslim & $4(1.4 \%)$ & $6(2.2 \%)$ \\
\hline Other & $0(0.0 \%)$ & $2(0.7 \%)$ \\
\hline \multicolumn{3}{|l|}{ Mother's education } \\
\hline No education & $22(8.0 \%)$ & $25(9.1 \%)$ \\
\hline Primary & $37(13.4 \%)$ & $85(30.8 \%)$ \\
\hline Secondary & $25(9.1 \%)$ & $45(16.3 \%)$ \\
\hline Above secondary & $8(2.9 \%)$ & $29(10.5 \%)$ \\
\hline \multicolumn{3}{|l|}{ Mother's occupation } \\
\hline Housewife & $55(19.9 \%)$ & $92(33.3 \%)$ \\
\hline Farmer & $0(0.0 \%)$ & $2(0.7 \%)$ \\
\hline Merchant & $16(5.8 \%)$ & $39(14.1 \%)$ \\
\hline Government employee & $13(4.7 \%)$ & $24(8.7 \%)$ \\
\hline Self-employee & $8(2.9 \%)$ & $21(7.6 \%)$ \\
\hline Others & $0(0.0 \%)$ & $6(2.2 \%)$ \\
\hline \multicolumn{3}{|l|}{ Father's education } \\
\hline No education & $9(3.3 \%)$ & $14(5.1 \%)$ \\
\hline Primary & $32(11.6 \%)$ & $44(15.9 \%)$ \\
\hline Secondary & $32(11.6 \%)$ & $95(34.4 \%)$ \\
\hline Above secondary & $19(6.9 \%)$ & $31(11.2 \%)$ \\
\hline \multicolumn{3}{|l|}{ Father's occupation } \\
\hline Merchant & $19(6.9 \%)$ & $37(13.4 \%)$ \\
\hline Government employee & $24(8.7 \%)$ & $46(16.7 \%)$ \\
\hline Self-employee & $37(13.4 \%)$ & $78(28.3 \%)$ \\
\hline Farmer & $9(3.3 \%)$ & $20(7.2 \%)$ \\
\hline Unemployed & $3(1.1 \%)$ & $3(1.1 \%)$ \\
\hline \multicolumn{3}{|l|}{ Residence } \\
\hline Urban & $71(25.7 \%)$ & $157(56.9 \%)$ \\
\hline Rural & $21(7.6 \%)$ & $27(9.8 \%)$ \\
\hline
\end{tabular}

\subsection{Maternal and Child Health Care Characteristics}

Among the study participants mothers, 65 (23.6\%) cases, and $127(46.0 \%)$ control were pregnant 2-5 times and 67 $(24.3 \%)$ cases and $122(44.2 \%)$ controls were given birth $2-5$ times. About $68(24.6 \%)$ cases and $127(46.0 \%)$ controls mothers had 2-5 children. From all child mothers, 33 (12.0\%) 
cases and $98(35.5 \%)$ controls were attended Antenatal care 4 times. While $75(27.2 \%)$ cases and $182(65.9 \%)$ controls attended postnatal care services. Sixty-seven $(24.3 \%)$ cases and $120(43.5 \%)$ control children were in the 2nd-4th birth order. Among mothers about, $71(25.7 \%)$ cases and 179 $(64.9 \%)$ controls were delivered at a health facility and $77 \%$ of cases and $99 \%$ of controls were delivered by skilled health professionals (Figure 1).
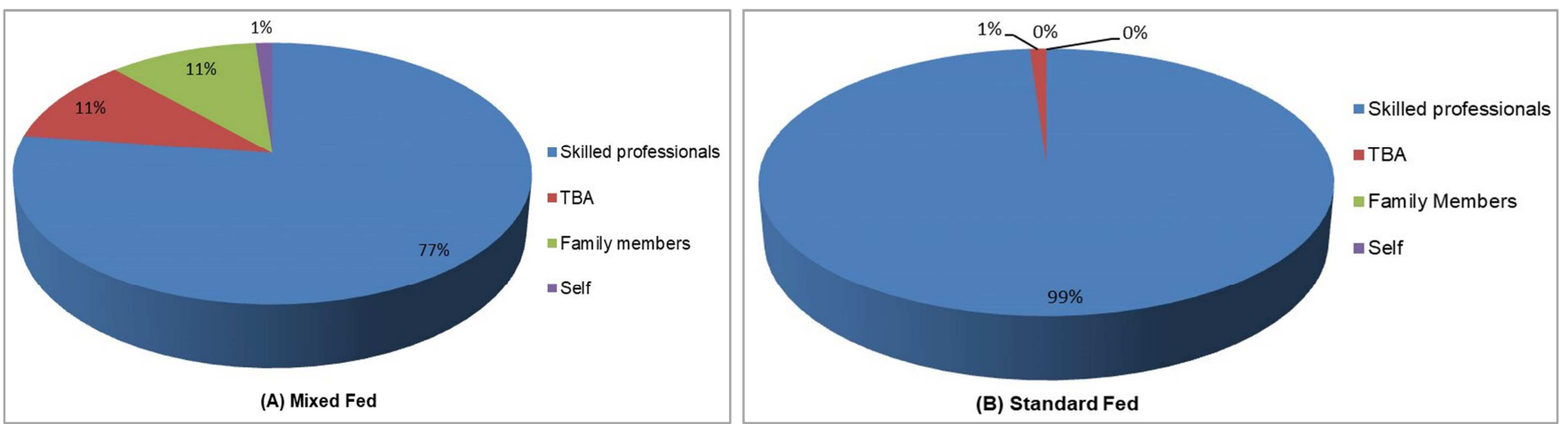

Figure 1. Delivery conducted among (A): mixed fed and (B): standard fed HIV positive mothers in Southern Ethiopia, 2019.

\subsection{HIV Care of Mothers and HIV Test Status of Children}

A total of $276 \mathrm{HIV}$ positive mothers, 70 (25.4\%) mixed infant fed mothers and $111(40.2 \%)$ standard infant fed mothers were received PMTCT service during pregnancy. The Median duration since HIV diagnosed was 5 years. Ninety-two
(33.3\%) cases and $173(62.7 \%)$ controls had good ARV adherence and also, $76(27.5 \%)$ cases and $132(47.8 \%)$ controls were in WHO clinical stage I. In the case of Mother PMTCT/ARV regimen $57(20.7 \%)$ cases and $153(55.4 \%)$ controls were received 1e (TDF-3TC-EFV) (Table 2).

Table 2. HIV care characteristics of HIV positive mothers in Southern Ethiopia 2019 (n: 276).

\begin{tabular}{|c|c|c|}
\hline \multirow{2}{*}{ Variables } & Cases (Mixed feeding) & Controls (Standard feeding) \\
\hline & n $(\%)=92$ & n $(\%)=184$ \\
\hline \multicolumn{3}{|c|}{ Time PMTCT service initiated } \\
\hline Pregnancy & $70(25.4 \%)$ & $111(40.2 \%)$ \\
\hline Delivery & $0(0.0 \%)$ & $8(2.9 \%)$ \\
\hline On ART & $20(7.2 \%)$ & $65(23.6 \%)$ \\
\hline None & $2(0.7 \%)$ & $0(0.0 \%)$ \\
\hline \multicolumn{3}{|c|}{ Duration Since HIV diagnosed in years } \\
\hline Median duration & 5 years & \\
\hline Less than 5 years & $33(12.0 \%)$ & $100(36.2 \%)$ \\
\hline Five and above & $59(21.4 \%)$ & $84(30.4 \%)$ \\
\hline \multicolumn{3}{|l|}{ ARV adherence } \\
\hline Good & $92(33.3 \%)$ & $173(62.7 \%)$ \\
\hline Fair & $0(0.0 \%)$ & $6(2.2 \%)$ \\
\hline \multicolumn{3}{|l|}{ WHO clinical stage } \\
\hline Stage I & $76(27.5 \%)$ & $132(47.8 \%)$ \\
\hline Stage II & $16(5.8 \%)$ & $52(18.8 \%)$ \\
\hline \multicolumn{3}{|c|}{ Mother PMTCT/ARV regimen } \\
\hline 1c (AZT-3TC-NVP) & $32(11.6 \%)$ & $23(8.3 \%)$ \\
\hline 1d (AZT-3TC-EFV) & $1(0.4 \%)$ & $6(2.2 \%)$ \\
\hline 1e (TDF-3TC-EFV) & $57(20.7 \%)$ & $153(55.4 \%)$ \\
\hline $1 \mathrm{f}(\mathrm{TDF}+3 \mathrm{TC}+\mathrm{NVP})$ & $2(0.7 \%)$ & $2(0.7 \%)$ \\
\hline \multicolumn{3}{|l|}{ Infant ARV regimen } \\
\hline sdNVP & $92(33.3 \%)$ & $184(66.7 \%)$ \\
\hline
\end{tabular}

Abbreviations: ART, antiretroviral therapy; NVP, nevirapine; EFV, efavirenz; AZT, zidovudine; TDF, tenofovir; 3TC, lamivudine; sdNVP, Single dose of nevirapine; PMTCT, Prevention of mother-to-child transmission; WHO, World Health Organization.

\subsection{HIV Status of Children Born from HIV Positive Mothers}

HIV test results and mixed feeding practice of HIV positive mothers showed that about $1.8 \%(1.1 \%$ cases and
$0.7 \%$ controls) infants born from HIV positive mothers became HIV-positive which confirmed by DNA-PCR positive HIV results. However, $1.4 \%$ and $2.5 \%$ rapid antibody test positive were in mixed fed infants and in standard fed groups respectively (Figure 2). 


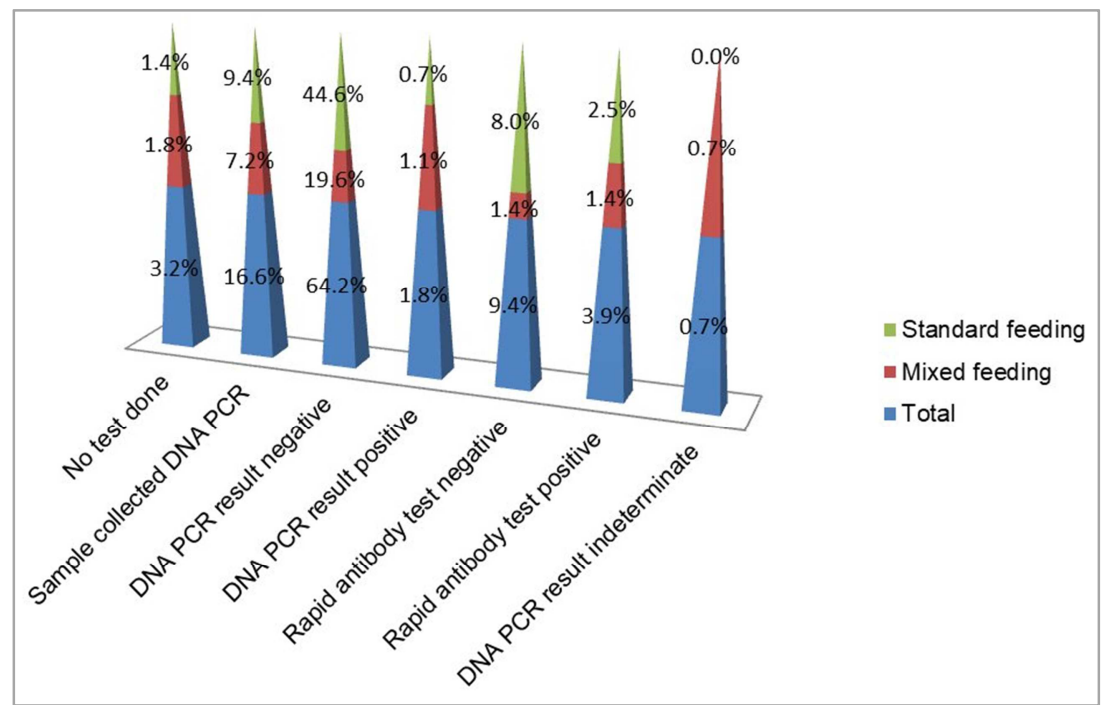

Figure 2. HIV test results of mixed fed and standard fed infants born from HIV positive mothers in Southern Ethiopia 2019.

Sixty-six (26.4\%) cases and $157(62.8 \%)$ controls were received advice on breastfeeding from health professionals. The median duration of breastfeeding was 6.0 months. About $6(2.2 \%)$ mixed feeding practiced and $17(6.2 \%)$ standard feeding practiced mothers were moderately underweight or thin $\left(16-18.5 \mathrm{~kg} / \mathrm{m}^{2}\right)$. Among the children involved in this study, 4 (1.4\%) mixed fed infants and 17 (6.2\%) standard fed infants had low birth weight $(<2.5 \mathrm{~kg})$ at birth.

\subsection{Determinants of Mixed Infant Feeding Practice Among HIV Positive Mothers}

In the study child sex, residence, mother's education, age group of mother, place of delivery, PNC service use, and duration since HIV diagnosed in years and WHO clinical stages were identified as predictors of mixed infant feeding practice in the binary logistic regression. Whereas, in the multivariate logistic regression analysis, age group of mother, place of delivery, duration since mother HIV diagnosed, and WHO clinical stage of the mother was identified as an independent determinant to mixed infant feeding practice among HIV positive mothers.

The age of the mother was one of the determinants of the mixed feeding practice of the mothers in the study area. The result showed that mothers within the age group 15-35years were 3.90 more in cases than in control counterparts $(\mathrm{AOR}=3.90 ; 95 \% \mathrm{CI}: 1.59-9.56)$. The result of the analysis confirms that the place of delivery is one of the significant predictors in the study; mothers who delivered at home were 8.79 times highly practiced mixed infant feeding than controls. (AOR=8.79; 95\% CI: 3.08, 25.10).

Duration since mother's HIV diagnosed was one of the risk factors of mixed infant feeding practice, those HIV positive mothers who diagnosed five and above years 1.85 times high risk of practicing mixed feeding than the controls (AOR=1.85 95: CI: 1.02-3.39). The mother of children with WHO Clinical Stage was one of the significant risk factors in the study area. Those HIV positive mothers with WHO Clinical stage I was 2.47 higher in cases than the controls $(\mathrm{AOR}=2.47 ; 95 \% \mathrm{CI}: 1.23,4.94)$. Determinants of mixed feeding practice are shown in Table 3.

Table 3. Determinants of Mixed Feeding Practice among HIV positive mothers in Southern Ethiopia 2019 (n: 276).

\begin{tabular}{|c|c|c|c|c|c|}
\hline Variables & $\begin{array}{l}\text { Cases (Mixed feeding) } \\
\mathrm{n}(\%)=92\end{array}$ & $\begin{array}{l}\text { Controls (Standard feeding) } \\
\mathrm{n}(\%)=184\end{array}$ & COR & AOR & p-value \\
\hline \multicolumn{6}{|l|}{ Sex of Child } \\
\hline Male & 44 (15.9) & $111(40.2)$ & 1 & 1 & \\
\hline Female & $48(17.4)$ & $73(26.4)$ & $1.66(1.00,2.75)$ & $1.33(0.75,2.36)$ & 0.329 \\
\hline \multicolumn{6}{|c|}{ Age of mother in yrs } \\
\hline $15-24$ & $7(2.5)$ & $53(19.2)$ & 1 & 1 & \\
\hline $25-35$ & $75(27.2)$ & $119(43.1)$ & $4.77(2.06,11.05)$ & $3.90(1.59-9.56)$ & $0.003 *$ \\
\hline $35+$ & $10(3.6)$ & $12(4.3)$ & $6.31(1.99-19.95)$ & $3.18(0.89-11.29$ & 0.074 \\
\hline \multicolumn{6}{|l|}{ Mother's education } \\
\hline No education & $22(8.0)$ & $25(9.1)$ & $3.19(1.21,8.42)$ & $1.26(0.42,3.80)$ & 0.679 \\
\hline Primary & 37 (13.4) & $85(30.8)$ & $1.59(0.66,3.78)$ & $1.14(0.45,2.89)$ & 0.776 \\
\hline Secondary & $25(9.1)$ & $45(16.3)$ & $2.01(0.80,5.07)$ & $1.81(0.68,4.80)$ & 0.235 \\
\hline Above secondary & $8(2.9)$ & $29(10.5)$ & 1 & 1 & \\
\hline \multicolumn{6}{|l|}{ Residence } \\
\hline Urban & $71(25.7)$ & $157(56.9)$ & 1 & 1 & \\
\hline Rural & $21(7.6)$ & $27(9.8)$ & $1.72(0.91,3.25)$ & $1.09(0.44,2.71)$ & 0.859 \\
\hline
\end{tabular}




\begin{tabular}{|c|c|c|c|c|c|}
\hline \multirow{2}{*}{ Variables } & \multirow{2}{*}{$\begin{array}{l}\text { Cases (Mixed feeding) } \\
\text { n (\%) }=92\end{array}$} & \multirow{2}{*}{$\begin{array}{l}\text { Controls (Standard feeding) } \\
\mathrm{n}(\%)=184\end{array}$} & \multirow{2}{*}{ COR } & \multirow{2}{*}{ AOR } & \multirow{2}{*}{ p-value } \\
\hline & & & & & \\
\hline One & $14(5.1)$ & 54 (19.6) & 1 & 1 & \\
\hline $2-5$ & $67(24.3)$ & $122(44.2)$ & $2.12(1.10,4.10)$ & $1.35(0.60,3.02)$ & 0.466 \\
\hline Above five & $11(4.0)$ & $8(2.9)$ & $5.30(1.79,15.68)$ & $1.12(0.25,4.97)$ & 0.878 \\
\hline \multicolumn{6}{|c|}{ Place of delivery } \\
\hline Home & $21(7.6 \%)$ & $5(1.8 \%)$ & $10.6(3.8-29.2)$ & $8.79(3.08,25.10)$ & $<0.001 *$ \\
\hline Health facility & $71(25.7 \%)$ & $179(64.9 \%)$ & 1 & 1 & \\
\hline \multicolumn{6}{|c|}{ Postnatal care usage } \\
\hline Yes & $75(27.2)$ & $182(65.9)$ & 1 & 1 & \\
\hline No & $17(6.2)$ & $2(0.7)$ & $20.63(4.65,91.49)$ & $3.91(0.44,34.85)$ & 0.222 \\
\hline \multicolumn{6}{|c|}{ Duration since HIV diagnosed in years } \\
\hline Less than 5 & $33(12.0)$ & $100(36.2)$ & 1 & 1 & \\
\hline Five and above & $59(21.4)$ & $84(30.4)$ & $2.13(1.27-3.56)$ & $1.85(1.02-3.39$ & $0.044 *$ \\
\hline \multicolumn{6}{|c|}{ WHO clinical stage } \\
\hline Stage I & $76(27.5)$ & $132(47.8)$ & $1.87(1.01-3.50)$ & $2.47(1.23-4.94)$ & $0.011 *$ \\
\hline Stage II & $16(5.8)$ & $52(18.8)$ & 1 & 1 & \\
\hline
\end{tabular}

Note: *Statistically significant at $\mathrm{p}$-value $<0.05 ; 1$ is Odds ratio for reference category

Abbreviations: COR, crude odds ratio; AOR, adjusted odds ratio; CI, confidence interval.

\section{Discussion}

In this study, the determinants of mixed infant feeding practice were age group of mother, place of delivery, duration since mother HIV diagnosed, and WHO clinical stage among HIV positive mothers. Mixed feeding was more practiced among HIV positive mothers who had female infants than male infants (17.4\% Vs $15.9 \%)$. This finding supported by Okanda et al in Kisumu [14].

The relationship between HIV test results of infants and mixed feeding practice of HIV positive mothers in the study showed that about $1.8 \%$ ( $1.1 \%$ cases and $0.7 \%$ controls $)$ infants born from HIV positive mothers were HIV-positive which was confirmed by DNA-PCR positive HIV results. This finding was supported by a study in Zimbabwe, Amhara Region of Ethiopia, and Gondar Town [15-17] indicates, HIV infection among children increased if the child was exposed to mixed feeding.

The finding of this study found that, the odds of mixed infant feeding practice among mothers within the age group 25-35years were 4-fold higher than the younger mothers (1524years). This might be due to those older mothers may be highly influenced by the cultural malpractices of feeding. Besides, when the age increases the mother disclosure to the husband increases. In addition, the father may refrain from caring for the mother or may leave the family and due to this case, mother may face economic problems. Then, she may force to practice mixed feeding when working additional time to raise her kids. However, the finding is in contradiction with the study result of Ladzani et al. in South Africa which indicated the older age of the mother was associated with recommended feeding [18].

Place of delivery was one of the significant predictors in the study, mothers who delivered at home were 9 times higher odds of practicing mixed feeding than standard feeding. This finding also agreed by studies in Addis Ababa, Gondar, Debremarkos, and South Nyanza, Kenya [17, 19-21]. This might be due to a mother who delivered at home may practice pre-lacteal feeding, other cultural foods, and this might relate with home-delivered mothers may lack strict attention to health professional advice about MTCT intervention options during delivery.

Duration since mother's HIV diagnosed was one of the risk factors which significantly associated, those mothers who diagnosed five and above years had 2 times higher odds to practice mixed infant feeding than the standard feeding counterparts. This might associate with those mothers with longer duration since diagnosed with HIV had lower fear for stigmatization and they coped with the situation then may return to malpractices which refrained from standards. Conversely, most studies showed an association between mothers practicing exclusive breastfeeding due to fear of stigmatization [13, 22, 23].

Mother of children with WHO Clinical stage-I was 3-fold higher odds to practice mixed infant feeding than the standard feeding practice. This might be due to mothers in the clinical stage I was at the early stage of HIV infection and they may frequently sick due to opportunistic infections and low adherence to ART drugs. Although, at the early HIV clinical stage mothers may lacks infant feeding counseling which made them liable to receive neighbors' advice about infant feeding options. This finding supported in Southwestern Nigeria [13]. Apart from strengths, this research had limitations including the use of maternal interviews about her feeding practice can be affected by recall bias and since the study was in the health institutions might give response favoring the care providers.

\section{Conclusion}

The study concludes that age of the mother, place of delivery, duration since mother HIV diagnosed, and WHO clinical stage of the mother was identified as determining factors of mixed Infant Feeding Practice among HIV positive mothers. There is a positive relationship between HIV test results of infants and mixed feeding practice of HIV positive mothers. We need to give an integrated infant feeding counseling with a practical demonstration to foster HIV positive mother's practice on infant feeding options. 
Moreover, the enhancement of health facility delivery, PMTCT, and ART services together with the implementation of WHO feeding global guideline for children born from HIV positive mothers were critically mandatory for the HIV free survival of children.

\section{Abbreviations}

AIDS-Acquired Immuno Deficiency Syndrome; DNAPCR-Deoxyribonucleic Acid-Polymerase Chain Reaction; HIV-Human Immuno Virus; IYCF- Infant and Young Child Feeding; PMTCT- Prevention of Mother-to-child Transmission; UNICEF-United Nations Children's Fund and WHO-World Health Organization.

\section{Ethics Approval and Informed Consent}

Approval for this study was provided by the Wachemo University, Research Ethical review committee. Permission to review charts was obtained from selected hospitals and data was obtained from mothers of children after obtaining written consent.

\section{Data Availability}

The datasets are available from the corresponding author upon reasonable request.

\section{Competing Interests}

The authors declare that they have no competing interests.

\section{Authors' Contributions}

BMG, EAT and BAK designed the study, guided the methodology, and BMG, EAT, BAK AND MMA wrote the first draft; BMG and EAT were responsible for reviewing of data analysis; BMG and MMA critically reviewed, discussed, and modified the manuscript. All authors read and approved the final manuscript for publication.

\section{Acknowledgements}

We would like to express our gratitude to all research participants, hospitals and Wachemo University.

\section{References}

[1] WHO U, UNAIDS U. HIV transmission through breastfeeding: A review of available evidence: World Health Organization. Geneva; 2004.

[2] Unicef. For every child, end AIDS: seventh stocktaking report, 2016. UNICEF; 2016.

[3] WHO U. Guideline: updates on HIV and infant feeding: the duration of breastfeeding, and support from health services to improve feeding practices among mothers living with HIV.
2016.

[4] De Cock KM, Fowler MG, Mercier E, et al. Prevention of mother-to-child HIV transmission in resource-poor countries: translating research into policy and practice. Jama. 2000; 283 (9): 1175-1182.

[5] Miller M, Iliff P, Stoltzfus RJ, Humphrey J. Breastmilk erythropoietin and mother-to-child HIV transmission through breastmilk. The Lancet. 2002; 360 (9341): 1246-1248.

[6] Coovadia HM, Rollins NC, Bland RM, et al. Mother-to-child transmission of HIV-1 infection during exclusive breastfeeding in the first 6 months of life: an intervention cohort study. The Lancet. 2007; 369 (9567): 1107-1116.

[7] Piwoz EG, Humphrey JH, Tavengwa NV, et al. The impact of safer breastfeeding practices on postnatal HIV-1 transmission in Zimbabwe. American journal of public health. 2007; 97 (7): 1249-1254.

[8] Taha TE, Kumwenda NI, Hoover DR, et al. The impact of breastfeeding on the health of HIV-positive mothers and their children in sub-Saharan Africa. Bulletin of the World Health Organization. 2006; 84: 546-554.

[9] Kuhn L, Sinkala M, Kankasa C, et al. High uptake of exclusive breastfeeding and reduced early post-natal HIV transmission. PloS one. 2007; 2 (12): e1363.

[10] Nlend AEN, Ekani BB. Trends of early infant feedings practices after counseling in infant born to HIV positive women in Yaoundé, Cameroon. The Pan African Medical Journal. 2014; 17.

[11] FMOH. Guideline for HIV Care/ART Clinical Mentoring in Ethiopia. Ministry of Health. 2015.

[12] FMOH. National strategy for infant and young child feeding. 2004.

[13] Aishat U, Olufunmilayo F, David D, Gidado S. Factors influencing infant feeding choices of HIV positive mothers in Southwestern, Nigeria. American Journal of Public Health Research. 2015; 3 (5A): 72-79.

[14] Okanda JO, Borkowf CB, Girde S, Thomas TK, Lecher SL. Exclusive breastfeeding among women taking HAART for PMTCT of HIV-1 in the Kisumu Breastfeeding Study. BMC pediatrics. 2014; 14 (1): 280.

[15] Ngwende S, Gombe NT, Midzi S, Tshimanga M, Shambira G, Chadambuka A. Factors associated with HIV infection among children born to mothers on the prevention of mother to child transmission programme at Chitungwiza Hospital, Zimbabwe, 2008. BMC public health. 2013; 13 (1): 1181.

[16] Berhan Z, Abebe F, Gedefaw M, Tesfa M, Assefa M, Tafere Y. Risk of HIV and associated factors among infants born to HIV positive women in Amhara region, Ethiopia: a facility based retrospective study. BMC research notes. 2014; 7 (1): 876.

[17] Muluye D, Woldeyohannes D, Gizachew M, Tiruneh M. Infant feeding practice and associated factors of HIV positive mothers attending prevention of mother to child transmission and antiretroviral therapy clinics in Gondar Town health institutions, Northwest Ethiopia. BMC public health. 2012; 12 (1): 240 
[18] Ladzani R, Peltzer K, Mlambo MG, Phaweni K. Infantfeeding practices and associated factors of HIV-positive mothers at Gert Sibande, South Africa. Acta Paediatrica. 2011; 100 (4): 538-542.

[19] Wakwoya EB, Zewudie TA, Gebresilasie KZ. Infant feeding practice and associated factors among HIV positive mothers in Debre Markos Referral Hospital East Gojam zone, North West Ethiopia. The Pan African medical journal. 2016; 24.

[20] Maru Y, Haidar J. Infant feeding practice of HIV positive mothers and its determinants in selected health institutions of Addis Ababa, Ethiopia. Ethiopian Journal of Health Development. 2009; 23 (2).
[21] Onono MA, Cohen CR, Jerop M, Bukusi EA, Turan JM. HIV serostatus and disclosure: implications for infant feeding practice in rural south Nyanza, Kenya. BMC public health. 2014; 14 (1): 390.

[22] Mohammed A, Shehu A, Aliyu A, Zoaka A. Infant feeding options, practices and determinants of feeding practices among HIV seropositive mothers in Abuja, Nigeria. Nigerian medical journal. 2010; 51 (1): 14.

[23] Aswa L. Study of factors affecting uptake of Exclusive Breastfeeding among HIV positive postnatal mothers in Kitwe urban district. MPH Thesis Department of Community Medicine, University of Zambia PubMed. 2010. 